\title{
GUIDELINES
}

\section{The CanPain SCI Clinical Practice Guidelines for Rehabilitation Management of Neuropathic Pain after Spinal Cord: screening and diagnosis recommendations}

\author{
S Mehta ${ }^{1,2}$, SD Guy ${ }^{1,2}$, TN Bryce ${ }^{3}$, BC Craven $^{4}$, NB Finnerup ${ }^{5}$, SL Hitzig ${ }^{4}$, S Orenczuk ${ }^{7}$, PJ Siddall ${ }^{8}$, \\ E Widerström-Noga ${ }^{9}$, A Casalino ${ }^{7}$, I Côté ${ }^{6}$, D Harvey ${ }^{10}$, A Kras-Dupuis ${ }^{7}$, B Lau ${ }^{11}$, JW Middleton ${ }^{8}$, \\ DE Moulin ${ }^{2,12}$, C O'Connell ${ }^{13}$, AG Parrent ${ }^{2,14}$, P Potter ${ }^{7}$, C Short ${ }^{15}$, R Teasell ${ }^{1,2,7}$, A Townson ${ }^{11}$, C Truchon ${ }^{16}$, \\ D Wolfe ${ }^{1,2,7}$, CL Bradbury ${ }^{4}$ and E Loh ${ }^{1,2,7}$
}

Study design: Clinical practice guidelines.

Objectives: To develop the first Canadian clinical practice guidelines for screening and diagnosis of neuropathic pain in people with spinal cord injury (SCl).

Setting: The guidelines are relevant for inpatient and outpatient SCI rehabilitation settings in Canada.

Methods: The CanPainSCI Working Group reviewed evidence to address clinical questions regarding screening and diagnosis of neuropathic pain after $\mathrm{SCl}$. A consensus process was followed to achieve agreement on recommendations and clinical considerations. Results: Twelve recommendations, based on expert consensus, were developed for the screening and diagnosis of neuropathic pain after $\mathrm{SCl}$. The recommendations address methods for assessment, documentation tools, team member accountability, frequency of screening and considerations for diagnostic investigation. Important clinical considerations accompany each recommendation.

Conclusions: The expert Working Group developed recommendations for the screening and diagnosis of neuropathic pain after $\mathrm{SCl}$ that should be used to inform practice.

Spinal Cord (2016) 54, S7-S13; doi:10.1038/sc.2016.89

\section{INTRODUCTION}

An international panel of experts—-the CanPainSCI Working Group (WG) - was formed to develop the first Canadian clinical practice guidelines (CPGs) to inform the management of at- and below-level neuropathic pain (NP) after spinal cord injury (SCI) in an inpatient and outpatient rehabilitation setting. Using a consensus-based, modified Grading of Recommendations Assessment, Development and Evaluation (GRADE) approach, recommendations have been made for three specific areas of management: screening and diagnosis, treatment and model of care. ${ }^{1}$ This paper focuses on the screening and diagnosis of NP.

Challenges in identifying and classifying pain in SCI

Diagnosing NP is a complex task requiring a combination of clinical skill and experience, validated assessment tools and relevant investigations, as a range of individual and environmental factors are implicated in the development of NP. ${ }^{2}$ In addition, despite the recognized high prevalence of pain post SCI, previous classifications of pain and definitions of pain types after SCI have not been consistent. ${ }^{3}$ This lack of consensus has delayed advances in developing a better understanding of factors contributing to the occurrence and maintenance of SCI-related pain, especially NP. ${ }^{4}$

Within the last 10 years, the published literature has increasingly discussed the need for standardizing the classification of NP and using SCI-specific assessment tools to screen for and diagnose NP. In the research setting, standardized pain classification enables more accurate categorization of study participants and, hence, more accurate comparison of outcomes. Consistent use of a widely adopted classification system provides a common, standardized language for communication among SCI health-care providers and researchers. Because of these factors, the International Spinal Cord Injury Pain (ISCIP) Classification was developed to standardize the classification of pain internationally. ${ }^{3}$ Despite this, however, the use of these standards across Canada has been inconsistent. ${ }^{5,6}$

\section{Challenges in measuring outcomes and collecting data}

A systematic review of the reliability, validity, sensitivity and practicality of various outcome measures for assessing pain after SCI in clinical trials found a lack of consensus about assessment domains and which tools to use. ${ }^{6}$ Importantly, the review noted that many of the

${ }^{1}$ Lawson Health Research Institute, London, Ontario, Canada; ${ }^{2}$ Western University, London, Ontario, Canada; ${ }^{3}$ Mount Sinai Hospital, New York, NY, USA; ${ }^{4}$ Toronto Rehabilitation Institute, Toronto, Ontario, Canada; ${ }^{5}$ Aarhus University, Aarhus, Denmark; ${ }^{6}$ Centre interdisciplinaire de reserche en réadaptation et integration sociale, Québec City, Québec, Canada; ${ }^{7}$ Parkwood Institute, London, Ontario, Canada; ${ }^{8}$ The University of Sydney, Sydney, New South Wales, Australia; ${ }^{9}$ University of Miami, Coral Cables, FL, USA; ${ }^{10}$ Spinal Cord Injury Ontario, London, Ontario, Canada; ${ }^{11}$ University of British Columbia, Vancouver, British Columbia, Canada; ${ }^{12}$ St. Joseph's Hospital, London, Ontario, Canada; ${ }^{13}$ Stan Cassidy Centre for Rehabilitation, Fredericton, New Brunswick, Canada; ${ }^{14}$ London Health Sciences Centre, London, Ontario, Canada; ${ }^{15}$ Dalhousie University, Halifax, Nova Scotia, Canada and ${ }^{16}$ Institut National d'Excellence en Santé et Services Sociaux, Montréal, Québec, Canada.

Correspondence: Dr E Loh, Department of Physical Medicine and Rehabilitation, Parkwood Institute, Main Building, 550 Wellington Road, London, Ontario, Canada N6C 0A7. E-mail: eldon.loh@sjhc.london.on.ca 
measures in current use require determination of validity and reliability in people with SCI. Lack of SCI-specific instruments to measure and describe pain, especially when combined with inconsistent classification of such pain, hinders efforts to understand pain in people with SCI, compare and interpret clinical studies, and advance both the understanding and management of pain in SCI. ${ }^{7,8}$ This is especially true for NP. ${ }^{4}$ Outcome measures must be reliable, valid and responsive. Standardization of the use of outcome measures in clinical practice and research would facilitate collaboration between clinical centres and the ability to interpret and apply research findings to advance the management of SCI-related pain. ${ }^{9}$

\section{Primary objective}

The Screening and Diagnosis Working Group (SDWG) was tasked with developing national clinical practice guidelines for screening and diagnosis of at- and below-level NP in SCI. The panel was provided with the following questions, based on a literature search, to guide the formulation of the recommendations: (1) Who should be screened for NP? (2) How should screening be performed? (3) How should NP be diagnosed? (4) How should pain be classified? (5) How should the responsiveness to treatment be measured? (6) How should a determination of failed therapy be made?

The objective of developing these guidelines was to assist SCI rehabilitation health-care providers in screening and diagnosing NP while being cognizant of other pain types.

\section{METHODS}

The SDWG was formed using the methodology described in the overview paper (this issue). To identify the relevant scientific literature, the steering committee searched MEDLINE, PsycINFO, EMBASE and

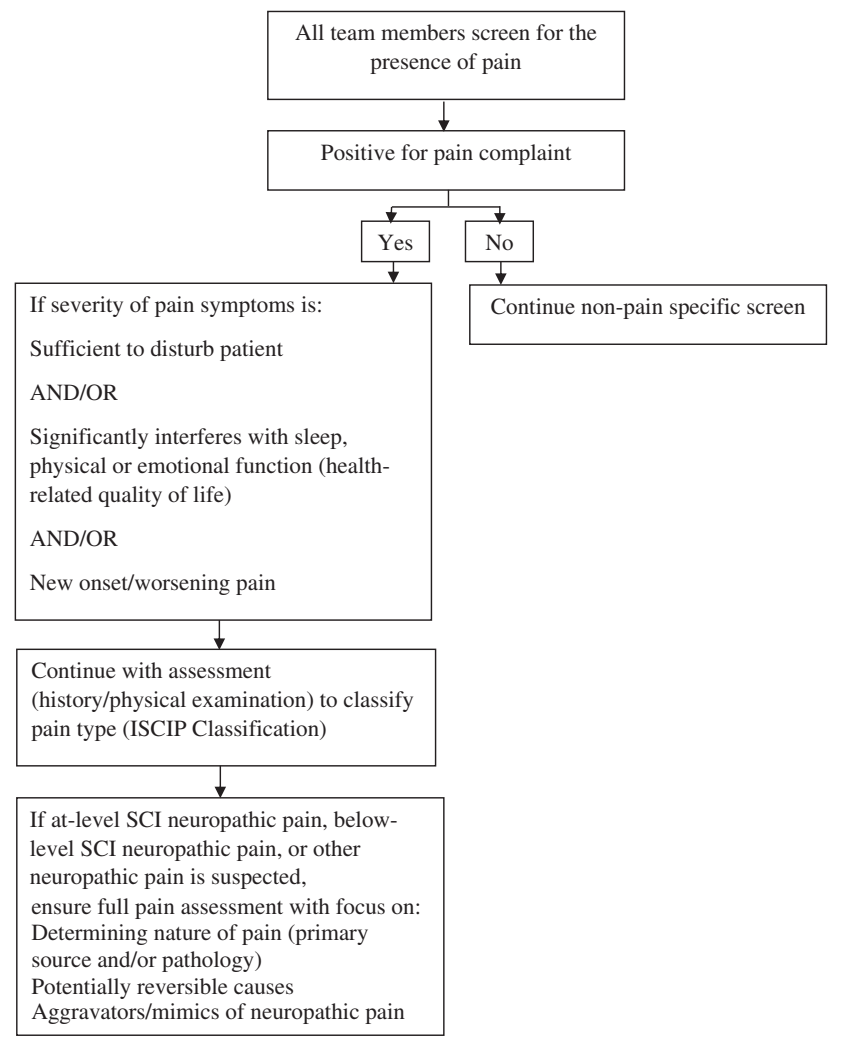

Figure 1 Screening and diagnosis algorithm for neuropathic pain in people with spinal cord injury.
CINHAL using the following search terms: spinal cord injury(ies), pain, neuropathic pain, classification systems and outcome measures. The steering committee also examined grey literature, using the Participation and Quality of Life (Par-QoL) website (http://www. parqol.com/), the Rehabilitation Measures Database (http://www. rehabmeasures.org/) and the Spinal Cord Injury Rehabilitation Evidence (SCIRE) website (http://www.scireproject.com/).

An analysis of classification systems involved a review of the 2006 National Institute on Disability and Rehabilitation Research (NIDRR) SCI Measures Meeting recommendations. ${ }^{6}$ The analysis of screeningand/or diagnosis-specific outcome measures included descriptions of the tool, the number of items included, cost to use the outcome measure, the scale system, administration, psychometrics and SCI-specific studies using the tool (Supplementary File 1). The analyses were presented to the SDWG to support recommendation development.

The SDWG then agreed upon the relevant areas of focus and met several times to develop draft recommendations for presentation to the entire CanPainSCI WG for review and discussion. Each recommendation was accompanied by relevant clinical considerations to facilitate knowledge translation. In addition, the SDWG developed a screening and diagnosis algorithm to guide clinicians in implementing the guidelines (Figure 1). Using the methodology described in the overview paper, the CanPainSCI WG discussed and voted on the final recommendations during a face-to-face meeting. Only those recommendations receiving at least $75 \%$ agreement were adopted and are included here.

\section{RESULTS}

Twelve recommendations for the screening and diagnosis of NP in people with SCI were developed. The lack of evidence in the literature on this topic precluded using a strict GRADE process to evaluate the literature and rate the levels of evidence. ${ }^{10}$ As a result, all recommendations are based on expert opinion. In addition, as the literature review revealed a lack of validated assessment tools specific to the SCI population, the experts agreed to consider pain outcome measures validated in other populations.

The group reviewed classification systems for $\mathrm{NP}^{3,11-17}$ and agreed upon the use of the ISCIP Classification as the standard approach to classifying pain (Supplementary File 2). The ISCIP Classification, which uses the International Association for the Study of Pain definition of pain, is a clinically relevant approach that has been tested for both utility and reliability. ${ }^{3,11}$ This system classifies pain into three tiers, with the first tier describing the type of pain (nociceptive, neuropathic or other), the second tier describing the pain subtype (musculoskeletal, visceral, or other for nociceptive and at level, below level, or other for neuropathic) and the third tier describing the primary pain source at the organ level and the pathology, if known.

In the ISCIP Classification, NP is defined as pain from a lesion or disease of the somatosensory nervous system. 'At-level NP' occurs in a distribution that falls within three dermatomes of the neurologic level of injury and not below, whereas 'below-level NP' occurs in a distribution that falls more than three dermatomes below the neurologic level of injury and may include the dermatomes of the level of neurological injury and three dermatomes below it. 'Other NP' may be localized above, at or below the neurologic level of injury but is pathologically unrelated to SCI. The other pain classification includes various types of pain or syndromes that do not meet the criteria for nociceptive or NP.

\section{Recommendation 1.1}

All patients with spinal cord injury must be screened for pain using a simple yes/no question. 
Type of evidence: expert opinion.

Clinical considerations. It is critical that pain be identified, as it is generally acknowledged to have a significant impact on functional abilities, quality of life, rehabilitation and community participation. Pain, including NP, is common with the literature reporting a large variability in the prevalence of pain overall (25-96\%) and of chronic pain $(20-77 \%) .3,18$

Early identification of pain and initiation of treatment could potentially decrease the physical and psychological morbidity associated with NP. Education about presumed aetiology can be helpful, especially for those with psychological distress related to experiencing NP. Progression of acute to chronic pain is an area of current research, and modification of risk factors for the development of chronic pain, and early and aggressive therapies, may prevent the development of chronic pain. ${ }^{19}$

Risk factors associated with the development of NP after SCI continue to be identified; thus, a high index of suspicion and routine screening is warranted for all patients. Risk factors that have been identified include older age at SCI, gunshot trauma causing SCI, onset of pain within a few weeks of SCI, early sensory hypersensitivity, (especially for cold stimuli post SCI), ${ }^{20}$ initial intense pain, continuous pain and associated conditions such as pressure ulcers, constipation and infection. ${ }^{21}$

\section{Recommendation $\mathbf{1 . 2}$}

Any member of the health-care team can, and should, screen for the presence of pain.

Type of evidence: expert opinion.

Clinical considerations. All team members should be aware of, and consider the impact of, pain on patient function, well-being and the ability to participate in activities of daily living. Patient screening should be conducted under the different and complementary contexts of the interdisciplinary team members.

\section{Recommendation 1.3}

Screening for pain should occur on admission to rehabilitation, regularly during inpatient rehabilitation and after discharge at each follow-up.

Type of evidence: expert opinion.

Clinical considerations. Early identification of pain and initiation of treatment could potentially decrease the morbidity associated with pain. In addition, repeated screening for pain should occur at any visit to a rehabilitation health-care provider, such as outpatient therapy or a physician visit.

\section{Recommendation 1.4}

If pain is present at screening, an assessment to determine the type of pain, its intensity and interference should be conducted.

Type of evidence: expert opinion.

Clinical considerations. Effective pain assessment includes information specific to the ISCIP classification tiers such as type, subtype, and level and identification of the different characteristics of pain and of functional interference, such as interference with physical activities, mood and sleep. ${ }^{8,22}$ Screening tools can identify patients with possible NP, but as these tools fail to identify about $10 \%$ to $20 \%$ of people with $\mathrm{NP}$ clinical assessment is a critical part of NP diagnosis. ${ }^{22}$

Comprehensive assessment of pain after SCI involves a thorough history and physical examination, and appropriate investigations to identify the (putative) aetiology of pain, the pain subtype classification and the main factors (such as psychosocial and environmental), modulating the pain experience. ${ }^{23}$ Although pain descriptors have relatively low specificity for diagnosing pain type, a dull aching pain in an area with preserved sensation is likely nociceptive, whereas a burning pain in an area without sensation is likely neuropathic. Psychosocial and environmental contributing factors, which include mood, cognitions, beliefs, social support, relationships, ergonomics and other factors, also need to be assessed, as effective pain management includes addressing both the pain itself and the contributing factors.

The ISCIP Classification standardizes communication between providers and enables the systematic description of pain in individuals with SCI. Different types of pain according to this classification require different treatment approaches. Pain severity, including its functional interference, also determines treatment approaches and the need for more in-depth assessment. The extent of interference may be assessed using the three corresponding items (interference with activities, mood and sleep) in the International Spinal Cord Injury Pain Basic Data Set (ISCIPBDS) v2.0. Use of a screening and diagnosis algorithm (Figure 1) can help the clinician determine whether additional assessment is required in the patient with at- or below-level NP. The algorithm lists criteria for additional assessment, including pain severity that disturbs the patient or significantly interferes with healthrelated quality of life and new onset or worsening pain.

\section{Recommendation 1.5}

Diagnosis of neuropathic pain, including its causes, should be informed by (1) a complete patient history, (2) a physical examination, (3) the International Spinal Cord Injury Pain (ISCIP) Classification system and (4) investigations.

Type of evidence: expert opinion.

Clinical considerations. A more detailed pain assessment should be conducted if the conditions in the decision tree associated with Recommendation 1.4 are met.

A complete patient history should focus on determining the nature of pain symptoms that could indicate potentially reversible causes, aggravators and/or mimics of NP, and the consequences of pain on function and quality of life. Essential elements of a complete patient history are the following:

- Nature of pain: onset or triggering event, position or location, quality (for example, burning, electric shock-like), radiation, severity, timing (for example, constant or intermittent, spontaneous or evoked) and aggravating or alleviating factors.

- Changes in neurologic status: changes in strength, sensation or spasticity.

- Associated symptoms: ask about red flag signs and symptoms such as vasomotor instability (refer to Recommendation 1.6, Clinical considerations).

- Screening for interference: interference with sleep, physical function and mood or emotional function.

- Recent changes in health: new medical diagnoses such as diabetes and other conditions predisposing to polyneuropathy.

- Additional historical components: based on presentation and suspected aetiology.

The physical examination should include, at a minimum, neurologic, skin and musculoskeletal examinations. Additional systems should 
be examined based on symptoms. Essential elements of the physical examination are the following:

- Vital signs.

- International Standards for Neurological Classification of Spinal Cord Injury (ISNCSCI).

- Reflexes, tone.

- Range of motion assessment of extremities, joint swelling or redness.

- Visual inspection of the skin for integrity.

- Calf measurement to assess for deep vein thrombosis.

- ISNCSCI autonomic standards.

- Additional physical examination components may be included based on presentation, for example:

o Primary abdominal region pain: abdominal screening examination.

- Respiratory involvement: chest assessment.

○ Autonomic symptoms: assessment for aetiology of autonomic dysreflexia (noxious stimuli).

Determining a specific aetiology can be difficult and may require additional investigations. Selection of these investigations is geared towards the diagnoses of greatest clinical likelihood, and diagnostic tests are based on the presentation. It is essential to image the appropriate area of the spinal cord for all patients with any change in neurologic status, such as changes in neurologic level, tone and reflexes. If any suspicion of urinary tract infection exists, it is important to perform a urinalysis and culture and sensitivity. Patients with primary abdominal region pain should have abdominal ultrasound, radiography or computed tomography as necessary to determine the source of the pain; blood work may include lipase, amylase, liver enzymes and kidney function tests. Signs and symptoms suggesting respiratory involvement could lead to further investigations such as chest assessment or radiography. In patients in whom pulmonary embolism is suspected, a computed tomogrpahy angiogram or ventilation/perfusion lung scan should be performed. Other investigations should be performed based on the differential diagnosis, as appropriate.

\section{Recommendation 1.6}

Assess for serious underlying conditions (red flags) that may cause, aggravate or mimic neuropathic pain and that require further investigation and prompt medical review.

Type of evidence: expert opinion.

Clinical considerations. Red flags are serious underlying conditions that may cause, aggravate or mimic NP. Red flag indicators are symptoms and signs that suggest that a particular condition may be present. It is essential to identify red flags, as effective treatment could significantly improve or eliminate NP if managed appropriately and if left untreated may have serious adverse consequences for the patient (Table 1).

\section{Recommendation 1.7}

Assess and manage psychosocial factors (yellow flags) that may contribute to pain-related distress and disability.

Type of evidence: expert opinion.

Clinical considerations. Addressing psychosocial factors (yellow flag conditions) is essential for treatment success in a person who has pain after SCI. Yellow flags can complicate and exacerbate the presentation of NP and may contribute to pain-related distress and disability. ${ }^{2}$ Examples of yellow flag conditions or factors include the following: ${ }^{2}$

- Depressive symptoms.

- Altered appetite.

- Poor motivation to complete daily activities or work because of pain.

- Decreased participation in valued activities.

- Pre-existing pain problems with evidence of poor adjustment.

- Avoidance of activities associated with pain.

- Extensive periods of rest or bed rest.

- Evidence of catastrophic thinking, preoccupation with pain prognosis, significant anxiety and panic symptoms.

- Use and dependence on alcohol or illicit substances.

- Increasing opioid dependence or misuse.

\section{Table 1 Red flags in patients with spinal cord injury}

\begin{tabular}{|c|c|c|}
\hline System & Red flag indicators & Red flag conditions \\
\hline Musculoskeletal & $\begin{array}{l}\text { History of recent trauma, visible deformity, changes in range of motion, new-onset } \\
\text { localized swelling and warmth }\end{array}$ & $\begin{array}{l}\text { Fracture or dislocation, heterotopic ossification, regional pathol- } \\
\text { ogy that may be contributing to NP presentation, and contracture }\end{array}$ \\
\hline Dermatologic & Redness, ulceration & Pressure ulcer, ingrown nail \\
\hline Cardiovascular & $\begin{array}{l}\text { Chest pain, shortness of breath, fevers, chills or sweats, autonomic symptoms, and } \\
\text { differences in calf measurements between left and right sides }\end{array}$ & $\begin{array}{l}\text { Abdominal aortic aneurysm, aortic dissection, myocardial infarc- } \\
\text { tion, infection and deep vein thrombosis }\end{array}$ \\
\hline Respiratory & As for cardiovascular & $\begin{array}{l}\text { Pulmonary embolism, deep vein thrombosis, infection or } \\
\text { pneumonia }\end{array}$ \\
\hline Urinary & $\begin{array}{l}\text { Changes in urine appearance or smell, pain over kidneys, new incontinence, leakage } \\
\text { between catheterizations, a history of renal or bladder calculi and scrotal or } \\
\text { testicular swelling }\end{array}$ & $\begin{array}{l}\text { Urinary tract infection or pyelonephritis, renal or bladder calculi, } \\
\text { urinary retention, testicular torsion and epididymitis }\end{array}$ \\
\hline Pelvic ${ }^{a}$ & Relation of pain to menstruation & Ovarian cysts, endometriosis and other genitourinary conditions \\
\hline Gastrointestinal $^{a}$ & Changes in bowel habit, examination findings of acute abdomen & $\begin{array}{l}\text { Stool impaction, constipation, acute abdomen, appendicitis and } \\
\text { cholecystitis }\end{array}$ \\
\hline Neurologic & $\begin{array}{l}\text { Changes in neurologic examination, such as increase or decrease in tone, decline in } \\
\text { motor or sensory neurologic level change in reflexes }\end{array}$ & Peripheral neuropathy, syringomyelia \\
\hline Other & Fever, chills, sweats and weight loss & Malignancy \\
\hline
\end{tabular}

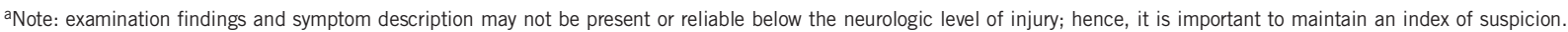


- Disruption of sleep quality and/or duration.

- Lack of support from family members towards pain and activity.

Recommendation 1.8

The International Spinal Cord Injury Pain Basic Data Set (ISCIPBDS) v2.0 should be used as a standardized tool for assessing and documenting pain in patients with spinal cord injury.

Type of evidence: expert opinion.

Clinical considerations. The ISCIPBDS v2.0 (Supplementary File 3) is a concise and a standardized way to document pain related to SCI; it is designed to be used to determine the location of pain relative to injury (above, at or below). ${ }^{17}$ ISCIPBDS is designed to be used in conjunction with the American Spinal Injury Association (ASIA) Impairment Scale (AIS) and the International SCI Core Data Set to evaluate SCIrelated pain. ${ }^{6,24}$ The revised tool is based on the minimum amount of the most critical and clinically relevant data to evaluate pain that can be collected in routine SCI clinical practice. The ISCIPBDS has been tested for reliability and validity. ${ }^{25,26}$

This valuable tool allows consistent communication and pain documentation across care providers and over time. Although interand intra-rater reliability still needs to be assessed, self-report items have established psychometric validity. ${ }^{26}$

\section{Recommendation 1.9}

Address patient concerns, expectations and needs as part of the neuropathic pain assessment.

Type of evidence: expert opinion.

Clinical considerations. It is vital to remember that pain is subjective, and people differ in their expectations of treatment and needs with regards to pain. As a result, it is important to develop rehabilitation goals and the treatment plan in partnership with the patient.

Goals of treatment, such as improvement in function, reduction in pain severity and improvement in mood, should be reviewed before initiating a particular treatment. Consider using SMART (Specific, Measurable, Agreed upon, Realistic and Time-based) goal methodology when setting treatment goals. ${ }^{27}$ Establishing specific treatment targets also allows evaluation of treatment benefit.

\section{Recommendation 1.10 + Recommendation 1.11}

Standardized evaluation of treatment response should be carried out by the health-care team at regular intervals.

Type of evidence: expert opinion.

The evaluation of treatment response should include assessment of changes in pain intensity, mood and function using the International Spinal Cord Injury Pain Basic Data Set (ISCIPBDS) v2.0. Evaluation also includes assessment of adverse events, aberrant behaviour and compliance.

Type of evidence: expert opinion.

Clinical considerations. These clinical considerations apply to recommendations 1.10 and 1.11. Monitoring a patient's response to treatment, including efficacy, tolerance, dose escalation and side effects, is vital to modifying any suboptimal treatments. Such modification should be performed as rapidly as feasible. Adverse events need to be balanced against treatment benefits when determining whether to continue treatment, and discussion with the patient should inform decision-making.

Comparing treatment targets with achieved outcomes helps determine whether continued use of a treatment is worthwhile. It is also important to assess domains of intensity, mood and function when determining treatment success. In addition to the ISCIPBDS v2.0, supplementary standardized measures such as the opioid risk tool may be used to evaluate outcomes not contained in the data set. As some medications to treat NP, such as opioids, are subject to misuse, it is important to monitor for aberrant behaviour, as this may indicate either misuse or inadequate pain control. The National Opioid Use Guideline Group provides additional recommendations for opioid use. $^{28}$

\section{Recommendation 1.12}

All patients with new-onset or worsening pain need to be reassessed. Type of evidence: expert opinion.

Clinical considerations. It is critical to pay particular attention to lateonset pain or sudden worsening of chronic pain. New-onset or worsening chronic NP may require exclusion of treatable causes of the pain, assessment for new-onset red flag or yellow flag conditions and a full NP assessment.

\section{DISCUSSION}

The recommendations in this document focus on the importance of using a standardized approach to screening and diagnosis of NP. Implementation of these recommendations in the clinical setting will differ because of varying needs and resources, depending on site location. The conditions existing at an individual site would determine which members of the rehabilitation team would complete each task outlined within the recommendations and clinical considerations. As a result, integrating actionable recommendations requires open discussion and consensus development by the team members. Operationalizing recommendations may also require training and mentoring for health-care providers to ensure an adequate comfort level with the task of screening and diagnosis.

Screening for pain at specific intervals creates a benchmark that fosters ongoing assessment of pain levels and monitoring of the success of management strategies during inpatient and community rehabilitation. An interdisciplinary approach to pain assessment may facilitate faster development of the optimal management strategy (this is further addressed in the paper describing a model of care).

Another integral principle in NP screening and diagnosis is standardizing the use of assessment tools to facilitate the sharing of information between clinicians in a consistent manner and comparing assessments across the patient's recovery continuum. The CanPainSCI WG was cognizant of the importance of selecting SCI-specific and validated pain screening and assessment instruments. Screening and assessment tools reviewed in the literature were more frequently geared towards NP in general than to SCI specifically, as Table 1 indicates. The SDWG assessed the evidence for each tool and found that the ISCIPBDS v2.0 allowed the most information to be captured effectively. As a result, integrating the ISCIPBDS v2.0 into clinical practice may assist in accurate diagnosis and facilitate optimal patient management.

Standardized assessments for the classification and documentation of NP are necessary, but a recently published environmental scan of SCI rehabilitation at 12 sites in Canada found significant regional differences (within and across provinces) in the use of standardized assessments for pain diagnosis or treatment, including validated tools for diagnosis of NP. ${ }^{29}$ In addition, a retrospective review of 100 patient charts from a Canadian SCI rehabilitation unit found suboptimal adherence to ISCIP standards for pain classification. ${ }^{5}$ Thus, there is a significant need to ensure the utilization of these standardized 
assessments across Canada to improve the management of NP after SCI.

The CanPainSCI WG was unable to apply the GRADE methodology to the body of evidence, due to a lack of published primary studies on NP screening and diagnosis in the SCI population. Much of the body of knowledge about NP screening and diagnosis is derived from the clinical expertise of the CanPainSCI WG, who contributed significant value to the development of these recommendations.

Another limitation of the current guidelines is the lack of inclusion of recommendations addressing the different domains of pain. Although the ISCIPBDS v2.0 effectively captures several domains including pain intensity and pain interference, many other domains are still lacking. Guidelines for reporting on core domains of chronic pain recommend inclusion of emotional functioning, patient global rating of change, adverse events and adherence to treatment. ${ }^{30,31}$ The SDWG was, however, unable to examine these domains because of the lack of evidence in the SCI population. Assessment of outcome measures for the different domains of pain after SCI determined that no consensus on the use of these tools could be reached because of their lack of reliability and validity in the SCI population. ${ }^{31}$

A fundamental need exists for studies examining the factor structure of pain assessment tools among the SCI population. Additional research evaluating the psychometric properties of SCI-specific outcome measures may help provide a more comprehensive assessment of an individual's pain condition.

\section{CONCLUSIONS}

$\mathrm{NP}$ is a common clinical problem in patients with SCI, with numerous challenges associated with screening and diagnosis. The CanPainSCI WG has addressed these challenges by developing a consistent and a practical approach to screening and diagnosis of NP in SCI rehabilitation. This approach comprises universal and frequent screening during inpatient and outpatient rehabilitation, formal assessment with accompanying investigations to characterize NP and the use of the ISCIPBDS v2.0 to assess and document pain.

\section{CONFLICT OF INTEREST}

BL has received consulting fees from the Northern Regional Health Authority (2014-2016), founded the CHANGEpain Clinic, has received fees for lecturing from DePuy and has served as expert witness. CO'C has received consulting fees from Bonify (2015-current), Lilly (2014) and Allergan (2013-current), has received lecture fees from Allergan, Biogen, Purdue, Lilly, Tweed, Tilray, Quality Respiratory Care and Respironics, has received grant support from Cytokinetics (2013- current), Biogen (2010-current), Acorda (2005-2010; 2015-current), Allergan (2010-current) and Sensimat 2015 and has served as expert witness on disability, at request of third parties including CMPA, insurance companies and law firms. TNB has received grant support from the Craig Neilsen Foundation (2015) and Allergan (2015). CC has received consulting fees from Allergan (2013) and the Rick Hansen Institute (2013) and has received grant support from the Rick Hansen Institute (2014-2016), the Ontario Neurotrauma Foundation (2011-2018), the Canadian Institutes for Health Research (2008- 2016) and the Rick Hansen Institute \& SCI Solutions Network (2012-2015). NF has received grant support from IMI Europain (EU/ EFPIA, 2009-2015). DM has received consulting fees from Johnson and Johnson (2014), fees for lecturing from Lilly (2014), Merck-Frosst (2014) and Purdue Pharma (2013), has received grant support from Pfizer (20092014) and has received book royalties from Cambridge University Press. PS has received grants from the Australian \& New Zealand College of Anaesthetists (2015) and the New South Wales state government (2013-2015) and holds a patent for a system and method for detecting pain and its components using magnetic resonance spectroscopy, US Patent 08755862, granted 17 June 2014. RT has received grant support (2013-2016) and lecture fees (2015) from Allergan. The remaining authors declared no competing interests

\section{ACKNOWLEDGEMENTS}

Funding for the research and publication of this supplement is provided by the Ontario Neurotrauma Foundation and the Rick Hansen Institute in their mission to advance the care of people with spinal cord injury (\#PM2 964). We thank Joanna Gorski for her help with manuscript preparation.

1 Schünemann H, Brożek J, Guyatt G, Oxman A (eds). GRADE Handbook for Grading Quality of Evidence and Strength of Recommendations. Updated October 2013. The GRADE Working Group, 2013. Available at http://gdt.guidelinedevelopment.org/central_prod/_design/client/handbook/handbook.html (accessed on 13 July 2015).

2 Siddall PJ, Middleton JW. Pain following spinal cord injury. In:Chhabra HS (ed.). ISCoS Textbook on Comprehensive Management of Spinal Cord Injuries. Wolters Kluwer: Gurgaon, Haryana, India. 2015 pp 825-848.

3 Bryce TN, Biering-Sørensen F, Finnerup NB, Cardenas DD, Defrin R, Lundeberg T et al. International spinal cord injury pain classification: part I. Background and description. March 6-7, 2009. Spinal Cord 2012; 50: 413-417.

4 Sawatzky B, Bishop CM, Miller WC, the SCIRE Research Team. Classification and measurement of pain in the spinal cord-injured population. Spinal Cord 2008; 46: $2-10$.

5 Janzen SE, Loh E, Mclntyre A, Mehta S, Teasell R. The diagnosis and treatment of pain on a spinal cord rehabilitation unit. Arch Phys Med Rehabil 2012; 93: e43.

6 Bryce TN, Budh CN, Cardenas DD, Dijkers M, Felix ER, Finnerup NB et al. Pain after spinal cord injury: an evidence-based review for clinical practice and research. Report of the National Institute on Disability and Rehabilitation Research Spinal Cord Injury Measures meeting. J Spinal Cord Med 2007; 30: 421-440.

7 Bryce TN, Dijkers MPJM. Assessment of pain after SCl in clinical trials. Top Spinal Cord Inj Rehabil 2006; 11: 50-68.

8 Bryce TN, Ragnarsson KT. Epidemiology and classification of pain after spinal cord injury. Top Spinal Cord Inj Rehabil 2001; 7: 1-17.

9 Widerström-Noga E, Biering-Sørensen F, Bryce T, Cardenas DD, Finnerup NB, Jensen MP et al. The International Spinal Cord Injury Pain Basic Data Set. Spinal Cord 2008; 46: 818-823.

10 Bryce TN, Biering-Sørensen F, Finnerup NB, Cardenas DD, Defrin R, Ivan E et al. International Spinal Cord Injury Pain (ISCIP) Classification: part 2. initial validation using vignettes. Spinal Cord 2012; 50: 404-412.

11 Bryce TN, Dijkers MP, Ragnarsson KT, Stein AB, Chen B. Reliability of the Bryce/Ragnarsson spinal cord injury pain taxonomy. J Spinal Cord Med 2006; 29: 118-132.

12 Cardenas DD, Turner JA, Warms CA, Marshall HM. Classification of chronic pain associated with spinal cord injuries. Arch Phys Med Rehabil 2002; 83: 1708-1714.

13 Putzke JD, Richards JS, Ness T, Kezar L. Test-retest reliability of the Donovan spinal cord injury pain classification scheme. Spinal Cord 2003; 41: 239-241.

14 Richards JS, Hicken BL, Putzke JD, Ness T, Kezar L. Reliability characteristics of the Donovan spinal cord injury pain classification system. Arch Phys Med Rehabil 2002; 83: 1290-1294.

15 Putzke JD, Richards JS, Ness T, Kezar L. Interrater reliability of the International Association for the Study of Pain and Tunks' spinal cord injury pain classification schemes. Am J Phys Med Rehabil 2003; 82: 437-440.

16 Siddall PJ, Yezierski RP, Loeser JD. Pain following spinal cord injury: clinical features, prevalence, and taxonomy. IASP Newsletter 2000; 3: 3-7.

17 Siddall PJ, Loeser JD. Pain following spinal cord injury. Spinal Cord 2001; 39: 63-73.

18 McGreevy K, Bottros MM, Raja SN. Preventing chronic pain following acute pain: risk factors, preventive strategies, and their efficacy. Eur J Pain Suppl 2011; 5: 365-372.

19 Finnerup NB, Norrbrink C, Trok K, Piehl F, Johannesen IL, Sørensen JC et al. Phenotypes and predictors of pain following traumatic spinal cord injury: a prospective study. J Pain 2014; 15: 40-48.

20 Margot-Duclot A, Tournebise H, Ventura M, Fattal C. What are the risk factors of occurrence and chronicity of neuropathic pain in spinal cord injury patients? Ann Phys Rehabil Med 2009; 52: 111-123.

21 Haanpää M. Are neuropathic pain screening tools useful for patients with spinal cord injury? Pain 2011; 152: 715-716.

22 Siddall PJ, Middleton JW. A proposed algorithm for the management of pain following spinal cord injury. Spinal Cord 2006; 44: 67-77.

23 Widerström-Noga E, Biering-Sørensen F, Bryce TN, Cardenas DD, Finnerup NB, Jensen MP et al. The International Spinal Cord Injury Pain Basic Data Set (version 2.0). Spinal Cord 2014; 52: 282-286.

$24 \mathrm{Kim}$ HR, Kim HB, Lee BS, Ko HY, Shin HI. Interrater reliability of the Korean version of the international spinal cord injury basic pain data set. Spinal Cord 2014; 52: 855-858.

25 Jensen MP, Widerström-Noga E, Richards JS, Finnerup NB, Biering-Sørensen F, Cardenas DD. Reliability and validity of the International Spinal Cord Injury Basic Pain Data Set items as self-report measures. Spinal Cord 2010; 48: 230-238.

26 Biering-Sørensen F, Charlifue S, DeVivo MJ, Grinnon ST, Kleitman N, Lu Y et al. Using the spinal cord injury common data elements. Top Spinal Cord Inj Rehabil 2012; 18: 23-27. 
27 Marshall R, Hasnan N. Team-based care. In: Chhabra HS (ed). ISCoS Textbook on Comprehensive Management of Spinal Cord Injuries. Wolters Kluwer: New Delhi, India. 2015, pp 414-422.

28 National Opioid Use Guideline Group Canadian Guideline for Safe and Effective Use of Opioids for Chronic Non-Cancer Pain 2010. Available at http://nationalpaincentre. mcmaster.ca/opioid/ accessed on 10 August 2015.

29 Craven C, Verrier M, Balioussis C, Wolfe D, Hsieh J, Noonan V et al. Rehabilitation Environmental Scan Atlas: Capturing Capacity in Canadian SCl RehabilitationRick Hansen Institute: Toronto, ON. 2012.

30 Turk DC, Dworkin RH, Allen RR, Bellamy N, Brandenburg N, Carr DB et al. Core outcome domains for chronic pain clinical trials: IMMPACT Recommendations. Pain 2003; 106: 337-345.

31 Alexander MS, Anderson KD, Biering-Sorensen F, Blight AR, Brannon R, Bryce TN et al. Outcome measures in spinal cord injury: recent assessments and recommendations for future directions. Spinal Cord. 2009; 47: 582-591. (c) (i) (5) $\ominus$ This work is licensed under a Creative Commons Attribution-NonCommercial-NoDerivs 4.0 International License. The images or other third party material in this article are included in the article's Creative Commons license, unless indicated otherwise in the credit line; if the material is not included under the Creative Commons license, users will need to obtain permission from the license holder to reproduce the material. To view a copy of this license, visit http://creativecommons.org/licenses/bync-nd/4.0/

(C) The Author(s) 2016

Supplementary Information accompanies this paper on the Spinal Cord website (http://www.nature.com/sc) 